\title{
Health-related quality of life in children with chronic conditions lodged at a comprehensive accommodation in the City of Buenos Aires
}

\author{
Camila Sánchez, M.D. ${ }^{a, c}$, Alfredo Eymann, M.D. ${ }^{b, c}$ and Carmen De Cunto, M.D. ${ }^{b, c}$
}

\begin{abstract}
Introduction. The treatment of chronic diseases usually requires a multidisciplinary professional training. There are comprehensive accommodations that are adapted to the needs of the families that have to stay away from home for long periods.

Objectives.To assess the impact of a comprehensive accommodation on the healthrelated quality of life of children with chronic conditions seen at a hospital of the City of Buenos Aires compared to children lodged at a traditional accommodation and to healthy children. To analyze the agreement between children's and caregivers' opinions.

Methods.Cross-sectional, observational study. Group 1:children with chronic conditions lodged at a comprehensive accommodation. Group 2: children with chronic conditions lodged at a traditional accommodation. Group 3: healthy children. The Argentineversion of theKidscreen-52 questionnaire was used. A value of $p<0.05$, the effect size $(E S)>0.20$, and the intraclass correlation coefficient (ICC) $>0.60$ were considered significant. Results. Two hundred and fifty children/caregiver dyads (50 in each chronic group and 150 healthy controls). Meanage: 12.6 years old (range: 8 -18years old); $56 \%$ were males. The children in Group 1 showed better moods and emotions, a better relationship with parents and peers, and a better school environment than those in Group $2(p<0.05$, ES > 0.20). Agreement between children's and caregivers' opinion was low, especially in relation to psychosocial dimensions (ICC $<0.29$ ).

Conclusions.In spite of their uprooting, children with chronic conditions are capable of maintaining a good relationship with their parents, a good peer bond and social support, and do not need discontinue their education while lodged at a comprehensive accommodation adapted to their needs during their stay in the City of Buenos Aires. Key words: health-related quality of life, chronic condition, children.
\end{abstract}

http:/ /dx.doi.org/10.5546/aap.2014.eng.231

\section{INTRODUCTION}

Any event resulting from a chronic disease could have an effect on the physical, psychological and social condition of patients and their families, especially because these patients are subjected to the constant need of medical supervision and prolonged treatments, among other factors. ${ }^{1,2}$

New definitions in the health field have promoted the development of questionnaires that allow to capture the multiple dimensions of health, such as the health-related quality of life (HRQoL). These instruments include the individual's perspective and gather information on their performance status and wellbeing, with a good correlation with pathophysiological indicators.

The Kidscreen-52 validated version has been available in Argentina since 2009. ${ }^{3}$

Over the past decades, major changes have taken place in the epidemiology of pediatric chronic conditions, for example, an increased survival in children who recover from a critical illness with sequelae and a greater awareness from health care professionals. It is estimated that $10 \%$ to $20 \%$ of the pediatric population in developed countries could have a chronic disease. ${ }^{5}$

In Argentina, concurrently with the gradual reduction in child mortality that has taken place since the 1980s, there are more and more children who suffer from a chronic health condition. ${ }^{6}$

Indicators such as mortality or survival rates, disability percentages or readmission rates are not enough to audit the effectiveness of care or even to provide an understanding of the situation for future proposals or even more to assess new pediatric interventions. ${ }^{7,9}$ The management of chronic conditions usually requires 
a multidisciplinary professional training. It is common that, at some point during treatment, families need to stay in a place near tertiary care facilities. In addition to health problems, this situation brings about social, family and financial problems, leading to uprooting, loss of job placements, family dissolution, transculturation and also higher costs on the health system. ${ }^{10}$ No studies have been found in the bibliography that consider the socio-economic and family impact of such migrations undertaken to seek treatment for a chronic illness. This is how new types of accommodations have emerged, which aim at providing housing for families who must stay away from their homes with the purpose of mitigating the impact caused by the chronic condition itself. These accommodations differ from traditional ones in that they offer entertainment programs and education in relation to social norms, hygiene and coexistence, thus allowing a comprehensive approach to the child's illness.

\section{OBJECTIVE}

To assess the impact of a comprehensive accommodation program on the HRQoL of children with chronic conditions seen at a hospital of the City of Buenos Aires compared to children lodged at a traditional accommodation and to healthy children. A secondary objective is to analyze the agreement between children's and caregivers' opinions.

\section{POPULATION AND METHODS \\ Study design}

Descriptive, cross-sectional, observational study.

\section{Ethical aspects}

The study was approved by the Research Protocol Ethics Committee of Hospital Italiano de Buenos Aires in March 2011.

\section{Study sample and participants}

Male and female children aged 8 to 18 years old, and their parents, who lived more than $100 \mathrm{~km}$ from the City of Buenos Aires (CABA) and were assisted at the Hospital Italiano de Buenos Aires were included.

The study was conducted between July 2011 and June 2012. During consultation, parents and participants were invited to take part in the study, parents provided their informed consent and the Kidscreen-52 questionnaire was delivered.
Inclusion criteria: being 8 to 18 years old, having voluntarily accepted to participate in the study, having a legal tutor who provided his/her informed consent, being lodged at the accommodation for more than one week, for the second time, or for the first time with a prolonged stay (more than three months).

Withdrawal criteria: inability to adequately reply the questionnaires or not answering enough questions (less than $80 \%$ of answers).

A comprehensive accommodation is defined as a lodging that offers the following: coordination with a nearby hospital through social workers, psychological support, continued education with home teachers, isolation as per medical requirements, sanitation appropriate to medical conditions, and a kitchen for each family. This study was done with patients who were staying at the Ronald McDonald House, located 200 meters from Hospital Italiano de Buenos Aires. A traditional accommodation is defined as a lodging that does not comply with any or none of the above described characteristics (for example: a hotel, a hostel or a temporary rental).

Samples were grouped as follows. Group 1 (G1): children with a highly complex chronic illness from different regions of the country, such as a transplant (e.g., liver, kidney, bone marrow), receiving cancer therapy, under prolonged study, or receiving a prolonged treatment for more than one month (e.g., anorexia nervosa, myelomeningocele, autoimmune disease) staying at a comprehensive accommodation. Group 2 (G2): same as G1 but staying at a traditional accommodation. Group 3 (G3): healthy children. The sample for G1 patients was consecutively obtained throughout the stipulated study period. Sampling of the other two groups were completed by convenience based on their condition (G2) and age (G3).

\section{Health-related quality of life assessment}

The children and parent versions of the self-administered Kidscreen-52 questionnaire were used, which have been validated and considered acceptably reliable in Argentina. ${ }^{11}$ The same questionnaire was administered to the mother, father or adult caregiver in their role as indirect informants. The Kidscreen-52 is a generic instrument that reports on ten HRQoL dimensions: physical well-being, psychological well-being, moods and emotions, self-perception, autonomy, parent relations and home life, social support and peers, 
school environment, social acceptance, and financial resources. The questionnaire uses a Likert answer scale to establish a score for each dimension, which is then standardized to a mean of 50 points and a standard deviation of 10 points. A higher score is indicative of a better HRQoL. ${ }^{12}$ The questionnaire was delivered and self-administered as of one week after the family started lodging in Buenos Aires because questions are related to the events in the past week.

\section{Outcome measures}

independent outcome measures were selected based on previous studies that showed a relationship with short and long term results on HRQoL. Outcome measures selected were parents' marital status and socio-economic level, established using a family material resources scale called Family Affluence Scale (FAS), which has an acceptable correlation with the parental employment modality category..$^{13}$ The FAS is estimated using four questions on the number of motor vehicles and computers owned by the family, if the participant has his/her own room, and having had family vacations over the last 12 months. The scale is categorized into low socio-economic level (score: $0-3$ ), middle socioeconomic level (score: 4-5), and high socioeconomic level (score: 6-7). The relationship among independent outcome measures and HRQoL was estimated based on the effect size (ES) only for G1. The questionnaire ends with an open question: "Is there anything else that you would like to comment on or that concerns you about your health?" Answers were grouped until saturating dimensions generated in children and caregivers.

\section{Statistical studies}

The sample was described by estimating absolute frequencies and percentages. Mean HRQoL dimension scores were compared by type of accommodation where families stayed while in Buenos Aires using Student's t test, and a value of $p<0.05$ was considered significant. The ES was calculated to establish the magnitude of differences in means, with values ranging from 0.20 to 0.50 considered small, from 0.51 to 0.80 , moderate, and $>0.80$, large. To analyze agreement between children's and parents' opinions, the difference in mean scores for each HRQoL dimension was estimated by subtracting the mean score indicated by the indirect informer from the mean score indicated by the child. A negative value suggests that the caregiver perceives a better well-being than the child, while a positive value suggests the opposite. Agreement analysis indicates how direct perception (that of children themselves) is similar or remarkably different from that of the indirect informer (the caregiver). To this effect, the intraclass correlation coefficient (ICC) was estimated. ICC values range from 0 to 1 , values above 0.6 are considered acceptable. The statistical software used was SPSS v 15.0 for Windows.

\section{RESULTS}

The final sample was made up of 250 children/ caregiver dyads who completed both questionnaires (50 in each chronic group and 150 healthy controls). No patients were withdrawn from the study.The sociodemographic characteristics of the participants are described in Table 1.

Significant differences were observed in the mean HRQoL scores of G1 and G2 participants: the children in G1 showed better moods and emotions, a better relationship with their parents and peers, and a better school environment, with no differences in terms of psychological well-being and autonomy. In comparison with the healthy control group, children in G1 had a better score in the self-perception dimension, but a worse score in the physical well-being, social acceptance and financial resource dimensions (Table 2).

When analyzing agreement between the opinions of parents and chronically-ill children $(\mathrm{G} 1+\mathrm{G} 2)$, scores were higher among children than among parents for most dimensions. The ICC ranged from 0.40 to 0.60 , with an acceptable ICC (ICC $=0.61$ ) only in the parent relations and school environment dimensions (Table 3).

The independent outcome measure analysis showed that the parents of $45 \%$ of patients were not in a stable relationship and, specifically in G1, children of separated parents had a lower score than children whose parents were living together at the time of the study. The effect of such differences was high in most dimensions. In relation to family socio-economic level, the higher the FAS, the higher the mean scores, with significant differences observed in almost every dimension (Table 4).

Both children and caregivers appeared to be very excited about taking part in the study and providing their comments at the end of the questionnaire. The most relevant answers by children were grouped into the following categories: answers related to the questionnaire $(30 \%)$ : "I really enjoyed completing the 
questionnaire," answers related to the disease (45\%): "I don't know how I'm going to live with my disease in the future," answers related to concerns ( $25 \%)$ : "I worry about my medications and the manufacturing pharmaceutical companies."

The most relevant answers by parents were grouped as follows: answers related to the accommodation (70\%): "Here I find more support than with my own family", "These parents understand and share what we are going through as a family," answers related to the disease (30\%): "My daughter said everything was OK in the questionnaire because we bought her a wig only yesterday."

\section{DISCUSSION}

Although an impact was observed in most dimensions among children with chronic conditions versus healthy controls, when

TABLE 1. Demographic characteristics

\begin{tabular}{|c|c|c|c|}
\hline & Group 1 (n: 50) & Group 2 (n: 50) & Group 3 (n: 150) \\
\hline Age of children & 12.7 years old (8-18 years old) & 13.1 years old (8-18 years old) & 12.01 yearsold (8-18 years old) \\
\hline 8-12 years old & $22(44 \%)$ & $14(28 \%)$ & $82(54.6 \%)$ \\
\hline $13-16$ years old & $13(26 \%)$ & $25(50 \%)$ & $37(24.6 \%)$ \\
\hline $17-18$ years old & $15(30 \%)$ & $11(22 \%)$ & $31(20.8 \%)$ \\
\hline \multicolumn{4}{|l|}{ Sex of the children } \\
\hline Male & $42 \%$ & $46 \%$ & $64 \%$ \\
\hline \multicolumn{4}{|c|}{ Sex of the accompanying parent/caregiver } \\
\hline Female & $82 \%$ & $76 \%$ & $70 \%$ \\
\hline \multicolumn{4}{|l|}{ Underlying disease } \\
\hline Cancer & $14(28 \%)$ & $5(10 \%)$ & \\
\hline Transplant & $11(22 \%)$ & $15(30 \%)$ & \\
\hline Neuromuscular disease & $8(16 \%)$ & $5(10 \%)$ & NA \\
\hline Autoimmune disease & $6(12 \%)$ & $7(14 \%)$ & \\
\hline Other & $11(22 \%)$ & $18(36 \%)$ & \\
\hline \multicolumn{4}{|l|}{ Nationality } \\
\hline Argentine & $100 \%$ & $100 \%$ & $100 \%$ \\
\hline \multicolumn{4}{|l|}{ Region of Argentina } \\
\hline NOA & $19(38 \%)$ & $13(26 \%)$ & \\
\hline NEA & $8(16 \%)$ & $11(22 \%)$ & \\
\hline Cuyo & $3(6 \%)$ & $16(32 \%)$ & NA \\
\hline Pampa & $14(28 \%)$ & $6(12 \%)$ & \\
\hline Patagonia & $6(12 \%)$ & $4(8 \%)$ & \\
\hline \multicolumn{4}{|l|}{ Stay in Bs. As. } \\
\hline$<2$ times & $9(18 \%)$ & $2(4 \%)$ & \\
\hline $2-5$ times & $23(46 \%)$ & $34(72 \%)$ & NA \\
\hline$>5$ times & $18(36 \%)$ & $12(24 \%)$ & \\
\hline \multirow{2}{*}{\multicolumn{2}{|c|}{ Length of stay in Bs. As. 23.5 days (7-140 days) }} & 16.7 days (7-90 days) & \\
\hline & & $32(64 \%)$ & \\
\hline $1-3$ months & $8(16 \%)$ & $13(26 \%)$ & NA \\
\hline$>3$ months & $9(18 \%)$ & $5(10 \%)$ & \\
\hline \multicolumn{4}{|c|}{ Socio-economic level (FAS) } \\
\hline Low $(0-3)$ & $32(64 \%)$ & $22(44 \%)$ & $21(14 \%)$ \\
\hline Middle (4-5) & $10(20 \%)$ & $15(30 \%)$ & $54(36 \%)$ \\
\hline High (6-9) & $8(16 \%)$ & $13(26 \%)$ & $75(50 \%)$ \\
\hline \multicolumn{4}{|c|}{ Marital status of the parents } \\
\hline Married & $27(54 \%)$ & $28(56 \%)$ & $66(44 \%)$ \\
\hline Separated & $23(46 \%)$ & $22(44 \%)$ & $84(56 \%)$ \\
\hline
\end{tabular}

Group 1: comprehensive accommodation; Group 2: non-comprehensive accommodation; Group 3: healthy controls.

NA: not applicable. NOA: Northwest region of Argentina. NEA: Northeast region of Argentina. FAS: Family Affluence Scale. 
comparing two similar populations (individuals with a chronic illness and surveyed in the context of uprooting), families staying at a comprehensive accommodation showed a better well-being. This may be facilitated by the support received by patients and families during their stay in the City of Buenos Aires. The vulnerability experienced by these families, together with the anxiety caused by the disease, leads to more suffering and fatigue, therefore interfering with their child's recovery. They also go through uprooting and lack of support from their extended

TABLE 2. Mean scores in the Kidscreen-52 dimensions, children

\begin{tabular}{|c|c|c|c|c|c|c|}
\hline & & $\mathbf{n}$ & Mean & Standard deviation & p value & ES \\
\hline \multirow{2}{*}{ Physical well-being } & G1/G2 & $50 / 50$ & $41.2 / 41.5$ & $9.2 / 7.8$ & NS & $\mathrm{NE}$ \\
\hline & G1/G3 & $50 / 150$ & $41.2 / 50.2$ & $9.2 / 13.4$ & 0.0001 & 0.7 \\
\hline \multirow[t]{2}{*}{ Psychological well-being } & G1/G2 & $50 / 50$ & $49 / 46.87$ & $8.89 / 5.03$ & NS & $\mathrm{NE}$ \\
\hline & G1/G3 & $50 / 150$ & $49 / 51.6$ & $8.89 / 9.2$ & NS & $\mathrm{NE}$ \\
\hline \multirow[t]{2}{*}{ Moods and emotions } & $\mathrm{G} 1 / \mathrm{G} 2$ & $50 / 50$ & $48.9 / 45.06$ & $11.7 / 6.2$ & 0.04 & 0.4 \\
\hline & $\mathrm{G} 1 / \mathrm{G} 3$ & $50 / 150$ & $48.9 / 47.7$ & $11.7 / 11.4$ & NS & $\mathrm{NE}$ \\
\hline \multirow[t]{2}{*}{ Self-perception } & $\mathrm{G} 1 / \mathrm{G} 2$ & $50 / 50$ & $53.4 / 49.2$ & $12.01 / 11.05$ & NS & $\mathrm{NE}$ \\
\hline & $\mathrm{G} 1 / \mathrm{G} 3$ & $50 / 150$ & $53.4 / 48$ & $12.01 / 11.02$ & 0.009 & 0.4 \\
\hline \multirow[t]{2}{*}{ Autonomy } & $\mathrm{G} 1 / \mathrm{G} 2$ & $50 / 50$ & $49.7 / 48.8$ & $10.7 / 5.4$ & NS & NE \\
\hline & $\mathrm{G} 1 / \mathrm{G} 3$ & $50 / 150$ & $49.7 / 49.2$ & $10.7 / 8.2$ & NS & NE \\
\hline \multirow{2}{*}{$\begin{array}{l}\text { Parent relations } \\
\text { and home life }\end{array}$} & G1/G2 & $50 / 50$ & $50.5 / 44.3$ & $14.2 / 6.2$ & 0.004 & 0.5 \\
\hline & G1/G3 & $50 / 150$ & $50.5 / 51.01$ & $14.2 / 11.6$ & NS & $\mathrm{NE}$ \\
\hline \multirow[t]{2}{*}{ Peers and social support } & G1/G2 & $50 / 50$ & $51.5 / 45.08$ & $14.02 / 6.1$ & 0.009 & 0.5 \\
\hline & $\mathrm{G} 1 / \mathrm{G} 3$ & $50 / 150$ & $51.5 / 50.2$ & $14.02 / 51.6$ & NS & $\mathrm{NE}$ \\
\hline \multirow[t]{2}{*}{ School environment } & G1/G2 & $50 / 50$ & $55.3 / 50.7$ & $13.7 / 7$ & 0.03 & 0.4 \\
\hline & $\mathrm{G} 1 / \mathrm{G} 3$ & $50 / 150$ & $55.3 / 52.3$ & $13.7 / 11.7$ & NS & NE \\
\hline \multirow[t]{2}{*}{ Social acceptance } & $\mathrm{G} 1 / \mathrm{G} 2$ & $50 / 50$ & $45.06 / 45.02$ & $13.2 / 9.5$ & NS & NE \\
\hline & G1/G3 & $50 / 150$ & $45.06 / 49.9$ & $13.2 / 12.9$ & 0.001 & 0.3 \\
\hline \multirow[t]{2}{*}{ Financial resources } & $\mathrm{G} 1 / \mathrm{G} 2$ & $50 / 50$ & $45.6 / 44.1$ & $10.2 / 12.3$ & NS & NE \\
\hline & G1/G3 & $50 / 150$ & $45.6 / 51.9$ & $10.2 / 11.9$ & 0.001 & 0.5 \\
\hline
\end{tabular}

Group 1: comprehensive accommodation; Group 2: traditional accommodation; Group 3: healthy controls.

NS: not significant. NE: no effect. ES: effect size

TABLE 3. Differences in mean scores and agreement between the opinions of children with chronic conditions and their caregivers

\begin{tabular}{lccccccccc}
\hline & $\mathbf{n}$ & \multicolumn{2}{c}{ Children } & \multicolumn{2}{c}{ Caregiver } & Difference among groups++ & ES & ICC \\
\hline & & Mean & SD & Mean & SD & Mean & SD & & \\
\hline Physical well-being & 100 & 41.3 & 9.2 & 38.6 & 7.14 & -2.7 & 11.77 & -0.2 & 0.41 \\
Emotional well-being & 100 & 48.2 & 8.89 & 48.1 & 9.4 & -0.1 & 12.11 & -0.01 & 0.45 \\
Moods and emotions & 100 & 46.9 & 11.7 & 46.2 & 13.6 & -0.7 & 11.92 & -0.06 & 0.03 \\
Self-perception & 100 & 51.3 & 12.01 & 45.9 & 7.9 & -5.4 & 10.99 & -0.4 & 0.03 \\
Autonomy & 100 & 44.7 & 10.7 & 46.3 & 10.68 & 1.6 & 11.09 & 0.14 & 0.42 \\
Parent relations & 100 & 47.4 & 14.2 & 51.16 & 10.9 & 3.76 & 13.9 & 0.27 & $0.77+$ \\
Social support and peers & 100 & 48.02 & 14.02 & 47.25 & 14.9 & -0.77 & 14.9 & -0.06 & 0.21 \\
School environment & 100 & 52.6 & 13.7 & 44.2 & 13.1 & -8.4 & 12.33 & $-0.75+$ & $0.60+$ \\
Social acceptance & 100 & 45.1 & 13.2 & 45.8 & 11.18 & 0.7 & 12.89 & 0.05 & 0.49 \\
Financial resources & 100 & 44.8 & 10.2 & 44.6 & 8.67 & -0.2 & 11.9 & -0.02 & 0.422 \\
\hline
\end{tabular}

ES: effect size (caregiver versus children); +: relevant ES (moderate/large effect).

++ : difference in scores between children and their caregivers.

ICC: intraclass correlation coefficient, acceptable if value is above 0.6. 
TABLE 4. Health-related quality of life dimensions in group 1 children in terms of their parents' marital status and socioeconomic level

\begin{tabular}{|c|c|c|c|c|c|c|c|c|c|c|}
\hline & $\begin{array}{c}\text { Marital } \\
\text { status (n) }\end{array}$ & Mean & SD & pvalue & Effectsize & $\begin{array}{c}\text { Financial } \\
\text { resources as } \\
\text { per FAS (n) }\end{array}$ & Mean & SD & pvalue & Effectsize \\
\hline Physical well-being & $\begin{array}{l}\text { C } 27 \\
\text { S } 23\end{array}$ & $\begin{array}{l}36.63 \\
34.51\end{array}$ & $\begin{array}{l}10.49 \\
10.55\end{array}$ & NS & $\mathrm{NE}$ & $\begin{array}{c}1(32) \\
2 \text { and } 3(18)\end{array}$ & $\begin{array}{l}34.62 \\
52.41\end{array}$ & $\begin{array}{l}10.49 \\
10.55\end{array}$ & 0.001 & 0.9 \\
\hline $\begin{array}{l}\text { Psychological } \\
\text { well-being }\end{array}$ & $\begin{array}{l}\text { C } 27 \\
\text { S } 23\end{array}$ & $\begin{array}{l}49.11 \\
47.34\end{array}$ & $\begin{array}{l}10.53 \\
12.24\end{array}$ & NS & $\mathrm{NE}$ & $\begin{array}{c}1(32) \\
2 \text { and } 3(18)\end{array}$ & $\begin{array}{c}47.12 \\
61.5\end{array}$ & $\begin{array}{l}9.29 \\
8.83\end{array}$ & 0.002 & 0.8 \\
\hline Moods and emotions & $\begin{array}{l}\text { C } 27 \\
\text { S } 23\end{array}$ & $\begin{array}{l}43.91 \\
51.34\end{array}$ & $\begin{array}{l}13.13 \\
14.69\end{array}$ & 0.02 & 0.5 & $\begin{array}{c}1(32) \\
2 \text { and } 3(18)\end{array}$ & $\begin{array}{l}51.34 \\
62.06\end{array}$ & $\begin{array}{l}13.13 \\
14.69\end{array}$ & 0.002 & 0.8 \\
\hline Self-perception & $\begin{array}{l}\text { C } 27 \\
\text { S } 23\end{array}$ & $\begin{array}{l}49.78 \\
39.22\end{array}$ & $\begin{array}{l}10.53 \\
12.24\end{array}$ & 0.003 & 0.8 & $\begin{array}{c}1(32) \\
2 \text { and } 3(18)\end{array}$ & $\begin{array}{r}48.7 \\
46.85\end{array}$ & $\begin{array}{l}10.53 \\
12.24\end{array}$ & NS & NE \\
\hline Autonomy & $\begin{array}{l}\text { C } 27 \\
\text { S } 23\end{array}$ & $\begin{array}{l}50.71 \\
48.79\end{array}$ & $\begin{array}{l}9.29 \\
8.83\end{array}$ & NS & NE & $\begin{array}{c}1(32) \\
2 \text { and } 3(18)\end{array}$ & $\begin{array}{l}39.21 \\
60.11\end{array}$ & $\begin{array}{c}10 \\
9.93\end{array}$ & 0.001 & 0.9 \\
\hline $\begin{array}{l}\text { Parentrelations } \\
\text { and home life }\end{array}$ & $\begin{array}{l}\text { C } 27 \\
\text { S } 23\end{array}$ & $\begin{array}{l}49.56 \\
45.79\end{array}$ & $\begin{array}{c}9.49 \\
9.7\end{array}$ & NS & NE & $\begin{array}{c}1(32) \\
2 \text { and } 3(18)\end{array}$ & $\begin{array}{l}45.79 \\
65.89\end{array}$ & $\begin{array}{c}9.49 \\
9.7\end{array}$ & 0.01 & 0.8 \\
\hline $\begin{array}{l}\text { Peers and } \\
\text { social support }\end{array}$ & $\begin{array}{l}\text { C } 27 \\
\text { S } 23\end{array}$ & $\begin{array}{l}46.61 \\
52.21\end{array}$ & $\begin{array}{c}11.9 \\
11.01\end{array}$ & 0.003 & 0.8 & $\begin{array}{c}1(32) \\
2 \text { and } 3(18)\end{array}$ & $\begin{array}{l}42.61 \\
54.87\end{array}$ & $\begin{array}{c}11.9 \\
11.01\end{array}$ & 0.0001 & 0.9 \\
\hline School environment & $\begin{array}{l}\text { C } 27 \\
\text { S } 23\end{array}$ & $\begin{array}{l}65.98 \\
65.98\end{array}$ & $\begin{array}{c}9.9 \\
9.13\end{array}$ & NS & $\mathrm{NE}$ & $\begin{array}{c}1(32) \\
2 \text { and } 3(18)\end{array}$ & $\begin{array}{l}65.98 \\
54.18\end{array}$ & $\begin{array}{l}11.96 \\
11.94\end{array}$ & 0.02 & 0.8 \\
\hline Social acceptance & $\begin{array}{l}\text { C } 27 \\
\text { S } 23\end{array}$ & $\begin{array}{l}42.27 \\
48.07\end{array}$ & $\begin{array}{l}16.28 \\
16.85\end{array}$ & 0.04 & 0.3 & $\begin{array}{c}1(32) \\
2 \text { and } 3(18)\end{array}$ & $\begin{array}{l}48.07 \\
35.79\end{array}$ & $\begin{array}{l}16.28 \\
16.85\end{array}$ & 0.01 & 0.8 \\
\hline Financial resources & $\begin{array}{l}\text { C } 27 \\
\text { S } 23\end{array}$ & $\begin{array}{l}41.91 \\
49.22\end{array}$ & $\begin{array}{c}9.9 \\
9.13\end{array}$ & 0.0001 & 0.9 & $\begin{array}{c}1(32) \\
2 \text { and } 3(18)\end{array}$ & $\begin{array}{l}50.25 \\
52.41\end{array}$ & $\begin{array}{c}9.9 \\
9.13\end{array}$ & NS & $\mathrm{NE}$ \\
\hline
\end{tabular}

$\mathrm{C}=$ cohabiting parents; $\mathrm{S}=$ separated or single parents.

Middle level = complete primary and/or secondary education.

High level $=$ complete tertiary or university education.

SEL 1 = low (score: $0-3$ ); 2 = middle (score: $4-5$ ); 3 = high (score: $>6$ ).

FAS: Family Affluence Scale.

family, which could have a negative impact and even lead to new diseases in the family group. Children perceived that they had a good peer bonding in their new environment, and they were not forced to discontinue their education. In this study, except for the physical well-being and financial resource dimensions (which is expected in children with a chronic disease and whose families face bigger expenses and even loss of income), all other dimensions were similar (or even better in the case of self-perception) when compared to the healthy children group, with whom ill children do not share the type of accommodation nor the health condition. It is known that children with chronic conditions generally have a worse quality of life. ${ }^{14}$ A study on HRQoL in pediatric liver transplant patients conducted in Argentina concluded that both the physical and psychosocial dimensions were more affected in transplanted children versus healthy children, but they were similar to those of juvenile idiopathic arthritis patients, and that family function was not affected. ${ }^{15}$ However, although the health status of chronically-ill children has significant consequences on everyday life, scores are usually higher than what healthy individuals expect and better than what physicians predict; purely physical factors are lower as subjects grow older and psychosocial factors become more relevant. Resilience (flexibility) usually enables individuals to adapt to adverse health conditions, therefore allowing most disabled children to have an acceptable quality of life. ${ }^{16}$ Even though physical factors do not disappear completely from the children's and families' reality, some persons grant them less significance. ${ }^{17}$

Agreement between children and caregivers in terms of HRQoL was low or regular across most dimensions, especially in relation to emotional domains, such as moods and emotions, selfperception and social support. Similar results were found in other studies, where a greater agreement was observed in relation to the physical dimensions and a lower agreement was found in terms of emotional or social aspects. These results point out the importance of having data provided by children themselves in relation to their HRQoL and that their caregivers' 
perspective may provide additional information that could help find conflictive areas that may affect the child-caregiver relationship. ${ }^{18}$

This study reflected how children of separated parents or widows indicated a worse quality of life in most dimensions. A study that assessed the impact of divorce on the HRQoL of children found significant differences in terms of psychosocial quality of life between joint and separated families, with a better HRQoL in relation to the time spent with the father when parents are separated by mutual agreement, when the mother has a university education, and when more time has elapsed since separation. ${ }^{19}$ Besides, the lower the family socio-economic level, the lower were the mean HRQoL scores. This finding is consistent with that of other studies, where the lowest psychosocial scores were found among the most disadvantaged social classes. ${ }^{20,21}$ Possible explanatory mechanisms for this effect could be the different level of access to material and social resources and the stress generated by these conditions on both children and parents. ${ }^{23}$

One of the study limitations is that it was conducted in a single hospital. However, the population included in the study was varied, with patients from all the regions of Argentina and from different social strata. Finally, it is worth noting that the study did not consider the time of disease progression, the type of underlying disease or its severity, the number of recent hospital admissions nor the type of treatment received. Recording such outcome measures may allow to detect major differences in the assessed aspects. Future studies with multivariate analysis could provide more information on the influence of independent outcome measures by type of accommodation.

\section{CONCLUSION}

HRQoL in children with a highly complex chronic illness was better when they have a higher socio-economic level, when their families were together, and when they stayed in a comprehensive accommodation while in the City of Buenos Aires.

\section{Acknowledgments}

To the Ronald McDonald House Medical Committee and to Susana Rodríguez, M.D., who helped with the statistical analysis.To Melina Caderosso, B.S., for processing data. Particularly, to the team of professionals and assistants who work at the Ronald McDonald House, who trusted on our research and opened its doors. We would also like to thank the children and their families who enthusiastically, patiently and selflessly participated in this study.

\section{REFERENCES}

1. Mastroyannopoulou K, Sclare I, Baker A, Mowat AP. Psycological effects of liver disease and transplantation. Eur J Pediatr 1998;157:856-60.

2. Taylor R, Franck L, Gibson F, Donaldson N, Dhawan A. The impact of Immunosuppression on Health Related Quality of Life in Adolescents after Liver Transplantation. Pediatr Transplant 2006;67:450-8.

3. BerraS,ButinofM. Adaptación transculturaldelcuestionario Kidscreen para medir calidad de vida relacionada con la salud en población argentina de 8 a 18 años. Arch Argent Pediatr 2009;107(4):307-14.

4. Weitzman M. Issues in the care of children with chronic illnesses. Medical Services. At: Hobbs N, Perrin JM, Ireys H. eds. Chronically ill children and their families. San Francisco: Jossey Bass; 1985. Págs.249-66.

5. DeSarasqueta P.Mortalidad neonataly posneonatalen recién nacidos de peso menor a $2500 \mathrm{~g}$ en la República Argentina (1990-1997). Arch Argent Pediatr 2001;99(1):58-61.

6. Staquet M. Hays R, Fayers M, eds. Quality of life assessment in clinical trials. Methods and practice. Oxford University Press, 1998.

7. Eiser C,Morse R. Quality of life measures in chronic diseases of childhood. Health Technol Assess 2001:5(4):1-157.

8. Spilker B. Quality of life and pharmacoeconomics in clinical trials. 2nd ed. Philadelphia: Lippincott-Raven Publishers; 1996.

9. Fernández NavarroJM, Barahona Clemente A, CañeteNieto P, Ortí Martínez P, et al. Hospitalización domiciliaria para niños con cáncer: Un paso más hacia la atención integral en oncología pediátrica. An Esp Pediatr 1998;48:1-3.

10. Berra S, Tebé C, Esandi ME, Carignano C. Fiabilidad y validez del cuestionario Kidscreen-52 para medir calidad de vida relacionada con la salud para población argentina de 8 a 18 años. Arch Argent Pediatr 2013;111(1):29-36.

11. Kidscreen Group Europe. The Kidscreen Questionnaires. Quality of LifeQuestionnaires for Children and Adolescents Handbook. Lengerich: Papst Science Publisher; 2006.

12. Currie CE, Elton RA, Todd J, Platt S. Indicators of socioeconomic status for adolescents: the WHO Health Behaviour in School-aged Children survey. Health Educ Res 1997;12(3):385-97.

13. Solans M, PaneS, Estrada MD, Serra-Sutton V, et al. HealthRelated Quality of Life Measurement in Children and Adolescents: A Systematic Review of Generic and DiseaseSpecific Instruments. Value Health 2008;11(4):742-64.

14. Sánchez C, Eymann A, De Cunto C, D’Agostino D. Quality of life in pediatric liver transplantation in a single-center in South America. Ped Transplant 2010;3:332-6.

15. Payot A, Barrington K. The Quality of Life of Young Children and Infants with Chronic Medical Problems: Review of the Literature. Curr Probl Pediatr Adolesc Health Care 2011;41:91-101.

16. Dinesen SJ, Greisen G. Quality of life in young adults with very low birth weight. Arch Dis Child Fetal Neonat Ed 2001;85(3):F165-9.

17. Albrecht GL, Devlieger PJ. The disability paradox: high quality of life against all odds. Soc Sci Med 1999;48(8):97788.

18. Eiser C, Morse R. Can parents rate their child's healthrelated quality of life? Results of a systematic review. Qual Life Res 2001;10:347-57. 
19. Eymann A, Busaniche J, Llera J, De Cunto C, Wahren C. Impact of divorce on the quality of life in school-age children. J Pediatr (Rio J) 2009;85(6):547-52.

20. Von Rueden U, Gosch A, Rajmil L, Bisegger C, et al. Socioeconomic determinants of health related quality of life in childhood and adolescence: results from a European study. JECH 2006;60:130-5.
21. Klatchoian D, Len C, Terreri M. Quality of life among children from São Paulo, Brazil: theimpact of demographic, family and socioeconomic variables. Cad Saúde Pública 2010;26(3):631-6.

22. Bradley RH, Corwyn RF. Socioeconomic status \& child development. Annu Rev Psychol 2002;53:371-99. 